\title{
Learning Together: Integration of Advanced Practice Providers into a General Medicine Ward Team
}

\author{
Emily Gottenborg, MD, Julia Limes, MD, Adam Olson, PA, and Brian Wolfe, MD \\ Department of Medicine, Division of Hospital Medicine, University of Colorado, Aurora, CO, USA.
}

\begin{abstract}
BACKGROUND: The Accreditation Council for Graduate Medical Education (ACGME) demands that physicians should be trained to engage in clinical activities with other health profession providers. Incorporation of advanced practice providers (APPs) into medicine ward teams has not yet been described.
\end{abstract}

AIM: To describe a pilot and feasibility evaluation of an interprofessional general medicine ward team with internal medicine residents and APPs to encourage resident leadership development, enhance service to education balance, and promote interprofessional collaboration.

SETTING: University of Colorado, Internal Medicine Residency Program.

PARTICIPANTS: Sixteen internal medicine residents, 16 interns, 19 Department of Medicine faculty members, and 8 advanced practice provider fellows in hospital medicine. PROGRAM DESCRIPTION: The authors describe an interprofessional general medicine ward team including team structure, and roles and responsibilities of each team member.

PROGRAM EVALUATION: Each team member completed an electronic survey following the rotation and the majority agreed that the pilot team allowed for an enhanced resident leadership role, and helped to restore the service to education balance and interprofessional collaboration. DISCUSSION: An interprofessional general medicine ward team is feasible, has the potential to optimize service to education balance, and exposes learners to a collaborative interprofessional clinical environment.

KEY WORDS: interprofessional education; advanced practice provider; interprofessional collaboration.

J Gen Intern Med 34(5):769-72

DOI: $10.1007 / \mathrm{s} 11606-019-04880-4$

(c) Society of General Internal Medicine 2019

\section{INTRODUCTION}

The Accreditation Council for Graduate Medical Education (ACGME) has created a core competency regarding interprofessional collaboration, emphasizing that physicians should be trained to engage in clinical activities with other health profession providers. ${ }^{1}$ Despite a growing number of advanced practice providers working in clinical settings, residents get minimal exposure to working with this profession. Advanced practice providers (APPs) are becoming a critical part of the workforce in hospitals and clinics, particularly within internal medicine specialties. ${ }^{2} 17.7 \%$ of over 123,000 practicing APPs practice in internal medicine or medicine subspecialties, suggesting that internal medicine residency graduates will increasingly work in clinical environments with APPs. ${ }^{3}$ There is minimal data to guide the best way to integrate resident trainees and APPs in a clinical setting, but a necessary first step is to expose physicians to APPs during their clinical training, so they can help describe the optimal practice structure in the future. ${ }^{4}$

The literature describes teams that integrate APP faculty members into resident teams including surgical teams, ICU teams, and medical consultation teams, with improvements in the resident workload and educational value of the rotation. ${ }^{5-7}$ However, there is no description of a general medical ward team integrating APPs and resident learners, or a shared educational rotation for both physician and APP trainees.

The traditional team structure for internal medicine residents during inpatient rotations consists of a supervising faculty attending, a senior resident acting as the team leader, and supervising interns and medical students, who are the direct providers of patient care. This model does not reflect the changing landscape of healthcare with an increasing emphasis on delivery of interprofessional care.

In this report, we describe the development, pilot, and feasibility of an interprofessional ward team model integrating advanced practice providers into a traditional medicine ward team.

\section{Setting}

This pilot occurred on the general medicine ward service at the University of Colorado Hospital, the largest clinical site of the Internal Medicine Residency Program. The team was piloted from July, 2016, to February, 2017, on a single general medicine team.

\section{Participants}

Participants included members of the general medicine ward teams: internal medicine residents and interns, Department of Medicine faculty members, and advanced practice provider fellows in hospital medicine. Sixteen residents, 16 interns, 8 advanced practice fellows (APFs), and 19 faculty attendings rotated on this team during the pilot period. The APFs were graduates of physician assistant or nurse practitioner pro-

Published online April 16, 2019 
grams, and licensed as advance practice providers, but who chose to pursue a 1-year intensive hospital medicine fellowship experience.

\section{PROGRAM DESCRIPTION}

\section{Strategic Taskforce}

In 2016, a taskforce was created including faculty from the School of Medicine, Internal Medicine Residency Program and Division of Hospital Medicine, and evaluated the current state of the general medicine ward team experience, and identified three key drivers of potential improvement activities. First, patient care duties were requiring more time and effort, as both complexity and hospital turnover increased. As a result, senior residents were performing more direct patient care and perceived that their ability to function as a team leader and educator was diminished. Second, all learners were reporting that the work load was increasing, with less time for educational activities. Third, residents interacted minimally with APPs in clinical environments, despite a growing presence of APPs. A concurrent opportunity was also identified: partnering with the hospital medicine fellowship for advanced practice providers within the University of Colorado that was created to address the local need for a prepared workforce of APPs to meet clinical demands.

The taskforce convened to design an integrated team model, incorporating an APF into the general medicine ward team. The team developed a framework to promote the optimal learning environment for each learner, with a purposeful focus on improving the resident experience, while also maintaining the educational experience of other learners on the team. The following guiding principles were created:

Resident as leader:

- Allow residents to enhance their leadership and teaching skills with multiple interprofessional learners

Service/education balance:

- Ensure each learner is appropriately challenged, but not burdened by, their individual patient care responsibilities

Interprofessional collaboration:

- Create an interprofessional learning environment where each learner had the opportunity to learn from and with each other

From these guiding principles, the team created the learning objectives and desired outcomes, as listed in Table 1.

\section{Pilot of New Team}

The team structure included an attending, a medicine resident, a medicine intern, an advanced practice fellow, and a third year medical student, as shown in Figure 1. The intern and APF held similar roles and acted as the primary providers for the patients, including an identical daily and weekly schedule.
Table 1 Objectives and Desired Outcomes for the Interprofessional Medicine Ward Team

\begin{tabular}{|c|c|}
\hline Objectives & Desired outcomes \\
\hline $\begin{array}{l}\text { 1) Resident will perform as the } \\
\text { team leader. }\end{array}$ & $\begin{array}{l}\text { - Senior resident carries fewer } \\
\text { individual patients } \\
\text { - Senior resident does not act as } \\
\text { first call for direct patient care } \\
\text { issues } \\
\text { - Resident practices teaching to } \\
\text { multiple learner levels }\end{array}$ \\
\hline $\begin{array}{l}\text { 2) Demonstrate service to } \\
\text { education balance (versus } \\
\text { educational balance) }\end{array}$ & $\begin{array}{l}\text { - Improve responses to residency } \\
\text { survey regarding workload and } \\
\text { ability to pursue educational } \\
\text { activities }\end{array}$ \\
\hline $\begin{array}{l}\text { 3) Illustrate interprofessional } \\
\text { collaboration in patient care }\end{array}$ & $\begin{array}{l}\text { - Understand the skill set and } \\
\text { capabilities of other professions } \\
\text { - Expose learners to an } \\
\text { interprofessional clinical } \\
\text { environment }\end{array}$ \\
\hline $\begin{array}{l}\text { 4) Maintain delivery of high- } \\
\text { quality, safe, and efficient patient } \\
\text { care }\end{array}$ & $\begin{array}{l}\text { - No negative impact on the } \\
\text { perception of safe and high-quality } \\
\text { care delivery by the team } \\
\text { - No impact on daily rounding } \\
\text { duration }\end{array}$ \\
\hline
\end{tabular}

This role included pre-rounding, presentation of care plan on rounds, writing all orders and notes, calling consultants, and organizing discharges. The team census was 12 , and the APF generally carried between 3 and 6 patients depending on their prior experience. Table 2 further describes the roles and responsibilities of each team member, and Table 1 describes the stated objectives and learner outcomes.

\section{PROGRAM EVALUATION}

\section{Outcomes}

Feasibility of this ward team was assessed by survey responses to an electronic survey. Each team member was sent an electronic survey following their rotation regarding their experience on the interprofessional ward team, using a 5-point Likert scale (strongly agree $\rightarrow$ strongly disagree), as summarized in

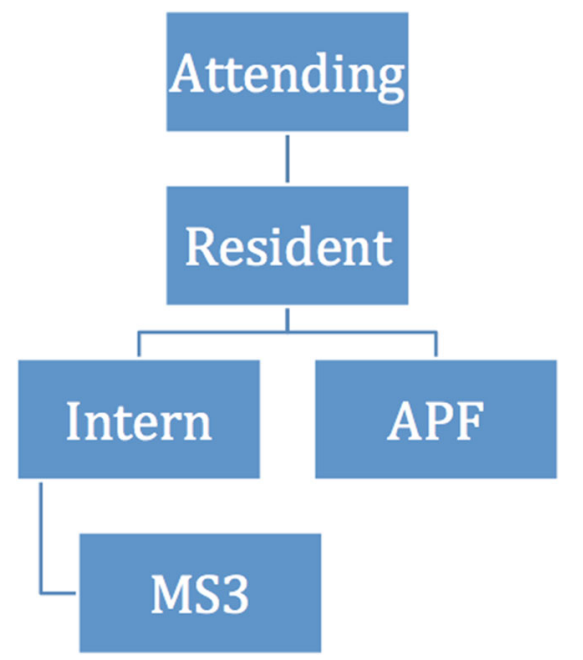

Figure 1 Team structure of the piloted general medicine ward team that integrated an APF into a resident team. 
Table 2 Team Member Responsibilities in the Interprofessional General Medicine Ward Team Model

\begin{tabular}{|c|c|}
\hline$\overline{\text { Role }}$ & Responsibility \\
\hline Attending & Supervision and oversight \\
\hline Resident & $\begin{array}{l}\text { Leader of daily rounds and clinical decision making } \\
\text { Manager of all patient care-related activities } \\
\text { Educator to multiple learner levels } \\
\text { Supervise intern, APF, MS3 in direct patient care }\end{array}$ \\
\hline Intern & $\begin{array}{l}\text { Primary provider and point person for } 6-8 \text { patients } \\
\text { Directly reports to resident for patient care-related } \\
\text { questions or concerns } \\
\text { Supervise the MS3 }\end{array}$ \\
\hline APF & $\begin{array}{l}\text { Primary provider and point person for } 3-6 \text { patients } \\
\text { Directly reports to resident for patient care-related } \\
\text { questions or concerns }\end{array}$ \\
\hline MS3 & $\begin{array}{l}\text { Primary provider and point person for } 3-6 \text { patients, shared } \\
\text { with intern } \\
\text { Directly reports to intern for patient care-related questions } \\
\text { or concerns }\end{array}$ \\
\hline
\end{tabular}

Table 3. All team members were surveyed on the following domains: (1) perception of team leadership, (2) perception of interprofessional collaboration, (3) quality and safety of care. The response rate was $100 \%$ for APFs (8/8) and $47 \%$ for residents (15/32). To assess the impact on service to education balance, the post-ward rotation survey was assessed for the response to the question, "Is the workload appropriate to allow adequate time to pursue educational activities?"

In response to "Is the workload appropriate to allow adequate time to pursue educational activities?", the background data showed that $48.5 \%$ of residents reported "Just Right" $(N$
137), in the year prior to this pilot. After this team went into effect, those who responded "Just Right" was 78.2\% (N 163).

\section{DISCUSSION}

The ACGME defines interprofessional care as one of their core competencies, and as a result GME leaders are investigating how to incorporate collaborative teambased care into their residency programs. We described a model incorporating advanced practice fellows into a general medicine ward team model as a feasibility pilot, and to assess our primary objectives: (1) allow the resident to perform as the team leader, (2) demonstrate service to education balance, and (3) illustrate interprofessional collaboration in care, without detriment to quality and safety measures.

Our background data suggested that residents on this ward rotation did not perceive themselves as the team leader, attributed to significant direct patient care duties. The addition of an APF, who had similar roles and responsibilities to the intern, enabled the resident to resume the role as team leader, with $100 \%$ of the residents agreeing that they encompassed the role of the leader in all daily activities. We suspect this is due to the ability to focus their efforts on developing team management and leadership skills, such as running daily rounds, creating comprehensive management plans, and teaching their learners, as the majority of residents did not carry individual

Table 3 Survey Response by Likert Scale Response

\begin{tabular}{|c|c|c|c|c|c|c|}
\hline & Survey question & $\begin{array}{l}\text { Strongly } \\
\text { agree, } \\
\%(N)\end{array}$ & $\begin{array}{l}\text { Agree, } \\
\%(N)\end{array}$ & $\begin{array}{l}\text { Neutral, } \\
\%,(N)\end{array}$ & $\begin{array}{l}\text { Disagree, } \\
\%,(N)\end{array}$ & $\begin{array}{l}\text { Strongly } \\
\text { disagree, } \\
\%(N)\end{array}$ \\
\hline \multicolumn{7}{|c|}{ Resident responses } \\
\hline \multirow[t]{4}{*}{$\begin{array}{l}\text { Objective } \\
1\end{array}$} & $\begin{array}{l}\text { The senior resident served as the team leader in all daily activities } \\
\text { including rounding, team management, and patient care } \\
\text { responsibilities. }\end{array}$ & $80(12)$ & $20(3)$ & $0(0)$ & $0(0)$ & $0(0)$ \\
\hline & $\begin{array}{l}\text { The senior resident carried fewer patients independently, than on other } \\
\text { ward teams without an APF. }\end{array}$ & $60(9)$ & $6.7(1)$ & $20.0(3)$ & $13.3(2)$ & $0(0)$ \\
\hline & $\begin{array}{l}\text { During rounds, the senior resident had fewer interruptions, such as } \\
\text { responding to pages or entering orders, than on medicine teams } \\
\text { without an APF. }\end{array}$ & $53.3(8)$ & $26.7(4)$ & $20.0(3)$ & $0(0)$ & $0(0)$ \\
\hline & I was able to practice teaching to multiple learner levels on my team. & $60(9)$ & $40(6)$ & $0(0)$ & $0(0)$ & $0(0)$ \\
\hline \multirow{3}{*}{$\begin{array}{l}\text { Objective } \\
3\end{array}$} & I worked on an interprofessional team. & $73.3(11)$ & $26.7(4)$ & $0(0)$ & $0(0)$ & $0(0)$ \\
\hline & $\begin{array}{l}\text { I understand the skill set and the capabilities of an advanced } \\
\text { practitioner provider in a clinical environment. }\end{array}$ & $6.7(1)$ & $60(9)$ & $20.0(3)$ & $6.7(1)$ & $6.7(1)$ \\
\hline & $\begin{array}{l}\text { Working with advanced practitioner providers prepared me for a future } \\
\text { clinical environment where I might practice. }\end{array}$ & $26.7(4)$ & $\begin{array}{l}66.7 \\
(10)\end{array}$ & $0(0)$ & $6.7(1)$ & $0(0)$ \\
\hline \multirow{3}{*}{$\begin{array}{l}\text { Objective } \\
4\end{array}$} & The care provided by my team was safe and effective. & $53.3(8)$ & $46.7(7)$ & $0(0)$ & $0(0)$ & $0(0)$ \\
\hline & $\begin{array}{l}\text { Having an additional team member, the APF, enhanced the safety and } \\
\text { quality of care provided. }\end{array}$ & $40(6)$ & $40(6)$ & $13.3(2)$ & $6.7(1)$ & $0(0)$ \\
\hline & The addition of an APF resulted in rounding inefficiencies. & $0(0)$ & $6.7(1)$ & $6.7(1)$ & $26.7(4)$ & $60(9)$ \\
\hline \multicolumn{2}{|c|}{ APF responses } & & & & & \\
\hline $\begin{array}{l}\text { Objective } \\
1\end{array}$ & $\begin{array}{l}\text { The senior resident served as the team leader in all daily activities } \\
\text { including rounding, team management, and patient care } \\
\text { responsibilities. }\end{array}$ & $50(4)$ & $50(4)$ & $0(0)$ & $0(0)$ & $0(0)$ \\
\hline Objective & I worked on an interprofessional team. & $33.3(2)$ & $33.3(2)$ & $33.3(2)$ & $0(0)$ & $0(0)$ \\
\hline \multirow[t]{2}{*}{3} & $\begin{array}{l}\text { I understand the skill set and the capabilities of an internal medicine } \\
\text { resident in a clinical environment. }\end{array}$ & $40(4)$ & $50(4)$ & $0(0)$ & $0(0)$ & $0(0)$ \\
\hline & $\begin{array}{l}\text { Working with medical residents prepared me for a future clinical } \\
\text { environment where I might practice. }\end{array}$ & $75(6)$ & $25(2)$ & $0(0)$ & $0(0)$ & $0(0)$ \\
\hline \multirow{2}{*}{ Objective } & The care provided by my team was safe and effective. & $100(8)$ & $0(0)$ & $0(0)$ & $0(0)$ & $0(0)$ \\
\hline & $\begin{array}{l}\text { My participation on the team enhanced the safety and quality of care } \\
\text { provided. }\end{array}$ & $75(6)$ & $25(2)$ & $0(0)$ & $0(0)$ & $0(0)$ \\
\hline
\end{tabular}


patients or have to field as many pages during rounds. One of the overarching goals of residency is to ensure clinical competency while also fostering the ability to supervise other healthcare providers in the future. Thus, this team structure enhances the resident's ability to serve as the team leader and supervise other learners in care delivery.

Background data also suggested that only approximately half of residents felt that the workload on the medicine ward teams was appropriate. The addition of an APF to this team helped to relieve the burden associated with a growing patient census, medical complexity, and more rapid turnover. Prior to the start of this pilot, there was concern that an additional early learner on a ward team would result in rounding inefficiencies, but in this feasibility assessment, there was no perceived detriment to rounding duration.

Finally, the delivery of high-quality healthcare requires a focus on interprofessional collaboration. APPs are increasingly incorporated into most clinical environments, and the future physician workforce should be equipped with the skills to work with these healthcare providers. This team enabled residents to be exposed to APPs in clinical practice, better understand their clinical capabilities, and work in a more realistic future model of care delivery. Only $75 \%$ of the resident respondents reported that they better understood the clinical capabilities of the APFs, which we hypothesize is due to the variability in individual performance of the APFs, related to varying clinical backgrounds. Ongoing exposure in other clinical setting may help residents better understand the roles of APPs.

Although we did not measure quality, safety, or efficiency metrics, we assessed the resident perception of care delivery. Both residents and APFs agreed that this team model provided safe and efficient care, and that the inclusion of the APF enhanced the safety and quality of care delivery. We suspect this is a result of an additional team member delivering direct patient care, without increasing the total team census. The senior resident also had more bandwidth to oversee all patient care, without being distracted by direct care of individual patients.

Disseminating this team model to other institutions is feasible, although it relies on the following factors: first, there must be the presence of a robust APP workforce and second, the agility to incorporate these providers into medical teams. While our institution had the benefits of an advanced practice provider fellowship program, this model could be used to incorporate advanced practice provide students, fellows, or faculty members.
This study has limitations. There was a low participant number during the assessment period, and although the response rate for the APFs was high, only approximately half of the residents who participated responded to the survey. We suspect this is due to frequent surveying leading to survey fatigue; however, it may present a response bias if those who felt more negatively or neutrally about the pilot opted not to respond.

Given early success with respect to educational outcomes and a robust framework to support ongoing residency initiatives, the interprofessional team model continues to grow and thrive at the University of Colorado Hospital. We hope that further expansion of this model helps to not only meet educational objectives and ACGME requirements, but also drives culture change in a landscape where collaboration across health professionals is essential to delivery of high-quality care. In summary, we described a feasible approach to an interprofessional general medicine ward team. Future directions should explore the optimal team structure and educational outcomes associated with interprofessional care delivery.

Corresponding Author: Emily Gottenborg, MD; Department of Medicine, Division of Hospital MedicineUniversity of Colorado, Aurora, CO 80045, USA (e-mail: emily.gottenborg@ucdenver.edu).

\section{Compliance with Ethical Standards:}

Conflict of Interest: The authors declare that they do not have a conflict of interest.

Publisher's Note: Springer Nature remains neutral with regard to jurisdictional claims in published maps and institutional affiliations.

\section{REFERENCES}

1. ACGME common program requirements. Available at: http://www. 6acgme.org/acgmeweb/Portals/0/PFAssets/ProgramRequirements / CPRs2013.pdf. Accessed 25 Jan 2016.

2. Lopes MA. Almeida AS, Almada-Lobo B. Handling the healthcare workforce planning with care: where do we stand? Hum Resource Health. 2015; $13: 38$

3. 2017 Statistical Profile of Certified Physician Assistants: An Annual Report of the National Commission on Certification of Physician Assistants. Available at: http://www.nccpa.net/research. Accessed 18 Jan 2019.

4. D'Arrigo T. Getting the most from advanced practice providers. December, 2016. Available at: https://acphospitalist.org/archives/2016/12/advanced-practice-providers.htm. Accessed 18 Jan 2019.

5. Fang M, Linson E, Suneja M, Kuperman EF. Impact of adding additional providers to resident workload and the resident experience on a medical consultation rotation. BMC Med Educ. 2017; 17(1): 44

6. Kahn SA, Davis SA, Banes CT, Dennis BM, May AK, Gunter OD. Impact of advanced practice providers (nurse practitioners and physician assistants) on surgical residents' critical care experience. J Surg Res. 1999;1: 712

7. Foster CB, Simone S, Bagdure D, Garber NA, Bhutta A. Optimizing Team Dynamis: An Assessment of Physician Trainees and Advanced Practice Providers in Collaborative Practice. Pediatr Crit Care Med. 2016;17(9):e430-6 